\title{
Safety and Efficacy of the Combination of Amitriptyline and Pregabalin SR in Severe Neuropathic Pain: Data of
} Logic Trial

\author{
Dr. Mayuresh Dilip Kiran*1, Lalit Pawaskar ${ }^{2}$, Shaheen Naseem Sheikh ${ }^{3}$ \\ ${ }^{1}$ Vice-President, Medical Services and Pharmacovigilance, Centaur Pharmaceuticals Pvt. Ltd. \\ ${ }^{2}$ Executive, Pharmacovigilance, Centaur Pharmaceuticals Pvt. Ltd. \\ ${ }^{3}$ Research Associate, Pharmacovigilance, Centaur Pharmaceuticals Pvt. Ltd.
}

\section{*Corresponding Author}

\section{Dr. Mayuresh Dilip Kiran}

Vice-President, Medical Services and Pharmacovigilance,

Centaur Pharmaceuticals Pvt. Ltd., Mumbai, India

Email: mayuresh_kiran@rediffmail.com

\begin{abstract}
Objective: To evaluate the safety and efficacy of the combination of Amitriptyline and Pregabalin SR in patients of severe neuropathic pain not controlled on monotherapy of a neuroanalgesic. Methods: LOGIC Study was conducted at 120 centres on 1269 patients across India. Patients above 18 years with severe neuropathic pain not controlled on monotherapy of a neuroanalgesic and who satisfied the inclusion and exclusion criteria were enrolled in the study. A combination of Amitriptyline and Pregabalin SR was given once daily. Patients were evaluated for the efficacy by visual analogue scale (VAS) and score was noted at 3 visits. Safety was evaluated through noting the adverse events occurring during the study. Change in mean VAS score, percentage of patients achieving $\geq 50 \%$ reduction in pain at every visit and Number Needed to Treat (NNT) was assessed. Results: Mean VAS score was 7.87 at baseline, 5.6 at day 7 and 3.42 at day $21.46 .4 \%$ and $84.6 \%$ of total patients at day 7 and 21 respectively had a reduction in pain of $\geq 50 \%$ from the baseline. NNT was calculated to be 1.19 for achieving $\geq 50 \%$ pain relief. Reduction in pain intensity was irrespective of blood glucose control, age and gender of the patient. Adverse effects were observed in 15 $\%$ patients of patients - Sedation, Dizziness, Dry Mouth and Constipation were predominant. Conclusion: Combination of Amitriptyline and Pregabalin SR is safe and efficacious in the treatment of severe neuropathic pain.
\end{abstract}

Keywords: Amitriptyline, Pregabalin, Severe Neuropathic Pain, NNT.

\section{Introduction}

Pain is an unpleasant sensory and emotional experience that can have a significant impact on a person's quality of life, general health, psychological health, social and economic wellbeing. The International Association for the Study of Pain (IASP 2011) has rightly defined neuropathic pain as 'pain caused by a lesion or disease of the somatosensory nervous system' at central or peripheral level. $^{[1]}$

Chronic pain is an enervating clinical condition associated with a variety of disease entities including diabetic peripheral neuropathy (DPN), postherpetic neuralgia, low back pathology, radiculopathy, fibromyalgia, and neurological disorders. ${ }^{[2]}$ It is most common and challenging but often neglected aspect of neurological disease. The most common reasons for neuropathic pain $(\mathrm{NeP})$ are radiculopathies, ${ }^{[3]}$ diabetic polyneuropathy ${ }^{[4],[5]}$ and nerve trauma, including postsurgical neuralgia. ${ }^{[6]}$ In population-based studies, the incidence of pain with neuropathic characteristics is $7 \%$ to $8 \%$ including mild cases with no need for symptomatic treatment. ${ }^{[7],[8]}$

The epidemiological assessments have strongly revealed that many patients with neuropathic pain do not receive appropriate treatment for their pain. ${ }^{[9]}$ This may be due to lack of diagnostic accuracy and relatively ineffective drugs, but also insufficient knowledge about effective drugs and their appropriate use in clinical practice. ${ }^{[10]}$ Evidence-based recommendations for the pharmacotherapy of NeP are therefore essential. Recent evidence-based guidelines, based on randomized controlled trials (RCTs) ${ }^{[11],[12],[13],[14],[15]}$ recommend tricyclic antidepressants (TCAs), gabapentinoids (gabapentin and pregabalin) as the first-line choices for $\mathrm{NeP}$. Although translational research efforts to develop more effective treatments and to address the current limitations of pharmacotherapy, combination drug regimens have been pursued by researchers and clinicians with the intention of improving outcomes. 


\section{International Journal of Innovative Research in Medical Science (IJIRMS) Volume 04 Issue 01 Jan 2019, ISSN: 2455-8737, Imp. Factor - 4.102 \\ Available online at $-\underline{w w w . i j i r m s . i n}$}

There are several guidelines recommending the role of Amitriptyline, a tricyclic antidepressant in treatment of chronic $\mathrm{NeP}$ and fibromyalgia. Interestingly, neuroanalgesia with antidepressant drugs are seen at doses below the drugs act as antidepressants. $^{[16]}$ TCAs, therefore, have analgesic properties independent of their antidepressant effects.

The neuropathic pain relieved by Amitriptyline is seen by blocking the sodium channels, ${ }^{[17]}$ reuptake of either norepinephrine (NE) or serotonin (SERT) ${ }^{[18]}$ and also by blocking hyperalgesia induced by N-methyl-D-aspartate agonists. Blocking the reuptake of these neurotransmitters prolongs their inhibitory action on the spinal cord neurons involved in transmitting pain. ${ }^{[18]}$ Moreover, it is reported that Amitriptyline may also have analgesic actions at other sites. ${ }^{[19]}$ Further, pharmacokinetic studies suggest Amitriptyline is extensively metabolized in the liver; the major active metabolite is nortriptyline which features distinctly potent NE and SERT reuptake inhibition after amitriptyline administration. ${ }^{[20]}$ Additional hydroxy metabolites apparently are active as well which may further enhance the neuroanalgesic (NA) activity. ${ }^{[21]}$ Yet another pharmacokinetic data postulated the bioavailability of Amitriptyline ranges from $33 \%$ to $62 \%$ after oral administration. ${ }^{[22]}$ The plasma half-life ranges from 10 to $28 \mathrm{~h}$ for Amitriptyline which can be accounted for single dosing. ${ }^{[23]}$ The evidences from previous studies have add on the effect by stating $30 \%$ pain reduction and global improvement in patients receiving TCAs compared with patients receiving placebo. ${ }^{[24]}$

Another NA, Pregabalin an analogue of gabapentin has been reported to show significant pain relief. Also, there are strong evidences of large RCTs that have revealed Pregabalin delivers significant pain relief and improved quality of sleep in postherpetic neuralgia, ${ }^{[25]}$ painful diabetic neuropathy ${ }^{[26]}$ or both. ${ }^{[27]}$ Few more studies have added on the efficacy in treating fibromyalgia with rapid and clinically substantial improvements related to core symptoms of the syndrome in patients with long-standing fibromyalgia. $^{[28]}$ This NA effect is due to binding to the presynaptic voltage-gated calcium channels in the dorsal horn, resulting in a decrease in the release of excitatory neurotransmitters such as glutamate and substance P. ${ }^{[29]}$ Moreover it is reported to manifest linear pharmacokinetics with higher affinity for the presynaptic calcium channel. Other pharmacokinetic data suggest oral bioavailability of Pregabalin is $90 \%$ with elimination halftime 4.8-6.3 hours. ${ }^{[30]}$

The literature corroborated demonstrates, combination therapy viz a viz. $\geq 2$ analgesic agents in the management of $\mathrm{NeP}$ is an attractive option. A pharmacotherapy with a combination may improve analgesic efficacy and has the potential to reduce the overall side effect profile. Also, synergistic effects may allow for dose reductions of combined drugs. ${ }^{[31]}$ Although, National Institute for Health and Care Excellence (NICE) guidelines, Neuropathic Pain Special Interest Group (NeuPSIG) and Canadian Pain Society (CPS) guidelines, in consistent with the European Federation of Neurological Societies (EFNS) guidelines suggest the use of either Amitriptyline or Pregabalin as first-line antineuropathic agents. ${ }^{[24],[32],[33]}$ Further, recommendations also highlight that if a TCA fails, switch to an anticonvulsant or vice versa. If a TCA provides only partial pain relief, add an anticonvulsant. ${ }^{[34]}$
Apart from the data assembled recent therapies are only grafting over the symptomatic relief devoid of preventing the progression and the dysfunction caused by series of etiologies associated with $\mathrm{NeP}$. The present trial was an approach to an application of the combination of Amitriptyline and Pregabalin. Although the pharmacokinetic studies of both Amitriptyline and Pregabalin have demonstrated different half-life which has pilled to the series of controversies stating irrational combination.

Hence, the present study involved, bilayered tablet consisting Amitriptyline as immediate release (IR) and Pregabalin sustained release (SR). This release pattern in the tablet would overcome the mismatched pharmacokinetics of both the study drugs. Thus, the current investigation was conducted with an aim to draw the efficacy of the recommended combination therapy in neuropathic pain uncontrolled by monotherapy.

\section{Methodology}

A systematic, multi-centered study was planned to evaluate the efficacy of Amitriptyline (10mg) + Pregabalin SR (75mg) on patients with known case of $\mathrm{NeP}$ at 50 trial centres. The study designed involved $1269 \mathrm{NeP}$ patients of either sex or age with $\geq 18$ years. 3 visits were planned per patient in the 3 week study duration at 0 (Baseline), 7 days and 21 days.

\section{Inclusion and Exclusion Criteria}

The study included patients of either the gender having age $\geq 18$ years. Patients diagnosed with NeP due to any cause including Diabetic Peripheral Neuropathy, Low Back Pain, Post Herpatic Neuralgia, Fibromyalgia and Spinal Cord Injury were included in study. Patients diagnosed with diabetes, and undergoing specific treatment for diabetes with antidiabetics were also recruited. Patients undergoing monotherapy with other neuroanalgesics with no improvement in reduction of pain symptoms and willing to adhere to the Protocol of the study were included in the study.

Patients with hepatic or renal impairment, taking MAO inhibiting drugs, history of urinary retention - BPH (Amitriptyline has anticholinergic action), evidence of Psychological disorder and hypersensitivity to study drugs were excluded from the study. Pregnant, lactating women and patients unwilling to give written Informed Consent were also excluded from this study.

\section{Study Intervention}

Study drug - A bilayered tablet containing a combination of Amitriptyline (10mg) + Pregabalin SR (75mg) was provided by the sponsor free of cost to the patient. Study dosage and administration - one tablet was taken once a day at $7.30 \mathrm{pm}$ with a glass of water.

\section{Study Procedure}

A multi-centered study was conducted on patients with neuropathic pain, satisfying the inclusion and exclusion criteria. The study involved medication (combination of Amitriptyline $10 \mathrm{mg}$ and Pregabalin $75 \mathrm{mg}$ SR), taken once a day at $7.30 \mathrm{pm}$. The patient will be evaluated for efficacy by the visual analogue scale (VAS) and will be asked for any adverse effects during the 3 visits planned in the 3 weeks study duration. The 3 visits are planned at 0 (Baseline), day 7 and day 21 . 


\section{International Journal of Innovative Research in Medical Science (IJIRMS) \\ Volume 04 Issue 01 Jan 2019, ISSN: 2455-8737, Imp. Factor - 4.102 \\ Available online at - www.ijirms.in}

\section{Study Design}

1269 patients with neuropathic pain were involved in the study and the results were evaluable Figure 1.
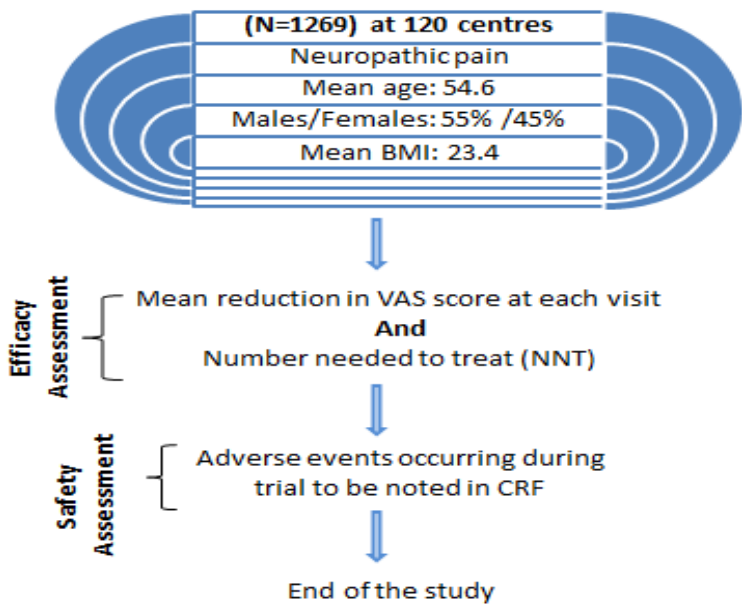

Figure 1: Schematic representation of study design (Consort flow chart)

\section{Concomitant therapy}

Pharmacological intervention and medication including other antidiabetics, anti-cholesterol and anti-hypertensives were allowed during the study duration. No other multi-vitamin and multimineral was allowed during the study interval. NonPharmacological interventions like exercise and proper diabetic diet intake at regular intervals were allowed and encouraged during the study duration.

\section{Efficacy assessment}

Efficacy assessment was done by measuring the visual analogue scale (VAS) score at each visit. The assessment of pain relief as a result of reduction in VAS score - (a) Mean reduction in VAS score at each visit (b) Percentage reduction in VAS score at each visit and (c) Number needed to treat (NNT) for achieving $>50 \%$ pain relief.

\section{Safety assessment}

Adverse events occurring during the clinical trial were noted in the CRF's. Naranjo's scale for probability assessment was used to know the relation of adverse events with the study drug.

\section{Regulatory and Ethical consideration}

The study drug is currently available in India and classified under schedule $\mathrm{H}$ drugs i.e. it can be sold only in the presence of a prescription of a registered medical practitioner. All the patients recruited in the study have read informed consent form and signed the same. Clinical trial protocol, ICF, CRF, undertaking by the investigators form, ethical committee certificates were collected before initiating the clinical study.

\section{Results}

\section{Efficacy assessment}

(a) Mean reduction in VAS score at each visit

The VAS score at baseline (day 0 ) was -7.87 which reduced to half score i.e. -4.2 at $3^{\text {rd }}$ visit (day 21).

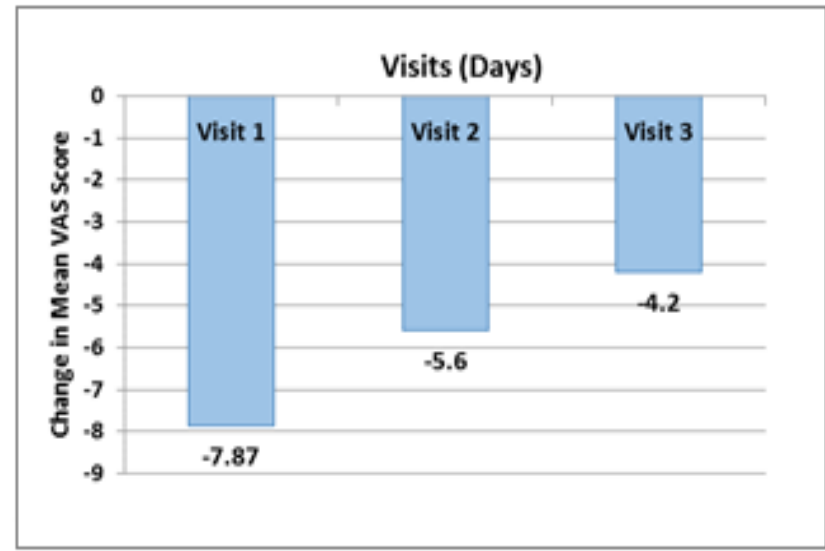

Figure 2: Mean reduction in VAS score at each visit

(b) Percentage reduction in VAS score at each visit

The data collected at each visit showed significant reductions in pain scores.

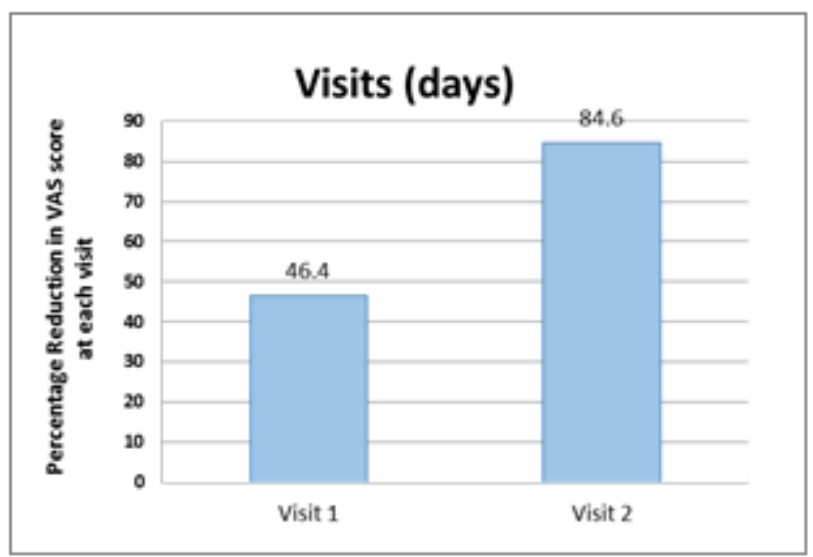

Figure 3: Percentage reduction in VAS score at each visit

(c) Number needed to treat (NNT) for achieving $\geq 50 \%$ pain relief.

To gain information regarding the overall efficacy of a drug NNT (the number of patients needed to treat to obtain one responder to the active drug) was used. Unless otherwise specified, we used the NNT for $50 \%$ pain relief. We did not use the number needed to harm because of lack of uniform criteria for assessing harmful events.

Table 1: Number needed to treat (NNT) for achieving $\geq 50 \%$ pain relief.

\begin{tabular}{|l|c|c|}
\hline $\begin{array}{l}\text { Number of patients who had } \geq 50 \% \\
\text { reduction in pain at visit } 3\end{array}$ & RR & NNT \\
\hline $84.6 \%$ & 0.846 & 1.19 \\
\hline
\end{tabular}

\section{Safety assessment}

There were no serious adverse events reported during the study. The adverse events of this study are reported in Table: 2 .

Table 2: Adverse events occurred during study

\begin{tabular}{|l|c|}
\hline Adverse events & Incidences in patients (\%) \\
\hline Dizziness & 4 \\
\hline Sedation & 15 \\
\hline Dry mouth and Constipation & 3 \\
\hline
\end{tabular}




\section{International Journal of Innovative Research in Medical Science (IJIRMS) Volume 04 Issue 01 Jan 2019, ISSN: 2455-8737, Imp. Factor - 4.102 \\ Available online at $-\underline{w w w . i j i r m s . i n}$}

\section{Discussion}

Several recommendations from NICE, NeuPSIG, CPS and EFNS guidelines have put forward the use of TCA along with anticonvulsants in treatment of severe NeP. This combination is not freely available in market or if available is not pharmacokinetically rational. Present study aimed at assessing the efficacy and safety of combination therapy of Pregabalin and Amitriptyline in patients with severe $\mathrm{NeP}$ in Indian population. This multi-centered study was conducted in severe NeP patients and to the authors knowledge this was the singlehanded study with pharmacokinetically corrected combination. The study has put forth ameliorating effects of Pregabalin and Amitriptyline combination with significant reduction in the VAS score from baseline -7.87 to -5.6 at visit 2 (day 7) and further reduction in VAS score to -4.2 at visit 3 (day 21). The percent reduction in pain at visit 2 was $46.40 \%$ which significantly reduced to $84.60 \%$. The NNT score which is termed as number needed to treat and achieve $\geq 50 \%$ of pain relief was 1.19 . Nearly every patient was benefited and had pain reduction of $\geq 50 \%$. Supported by the cognizance of several studies there are strong evidences stating neuroanalgesic effect of Amitriptyline. Numerous reviews of randomized, controlled trials have clinched that TCAs exhibit clear analgesic efficacy in a number of chronic pain conditions. ${ }^{[35-40]}$ Specifically, TCAs have demonstrated analgesia in pain caused by DPN, postherpetic neuralgia (for which there is a solid body of evidence to support efficacy), tension headache, migraine, atypical facial pain, fibromyalgia and low back pain. ${ }^{[41]}$

The first controlled double-blind crossover trial of the analgesic effect of Amitriptyline in patients who were not depressed was performed in patients with post herpetic neuralgia. The study was found to show good to excellent pain relief in 16 of 24 patients ( $p$ $\leq 0.001)^{[42]}$

Morello CM et al, has revealed the efficacy of Amitriptyline in DPN patients. The study concluded that there was moderate or greater pain relief by $14(67 \%)$ of 21 patients with Amitriptyline in comparison of Gabapentin (11 (52\%) of 21 patients). ${ }^{[43]}$

Moreover, a Cochrane database showed the efficacy of Amitriptyline in twenty-one studies (1437 participants) with median duration of six weeks. The study highlighted the combining classic neuropathic pain conditions of painful diabetic neuropathy $(\mathrm{PDN})$, postherpetic neuralgia (PHN) and post-stroke pain with fibromyalgia for second-tier evidence. There was a statistically significant benefit (risk ratio (RR) 2.3, $95 \%$ confidence interval (CI) 1.8 to 3.1) with a number needed to treat (NNT) of 4.6 (3.6 to 6.6) stating Amitriptyline should continue to be used as part of the treatment of neuropathic pain or fibromyalgia. ${ }^{[16]}$

Yasmin et al, in a multi-centered, prospective, open-labeled, single-arm, observational, 14-day study demonstrated fixed dose combination of 75 or $150 \mathrm{mg}$ sustained-release Pregabalin with combined with $1500 \mathrm{mcg}$ immediate release methylcobalamin. There was significant reduction $(P<0.05)$ in the proportion of patients having negative and positive symptoms associated with neuropathy, like hyperesthesia, paresthesia, tingling/numbness, burning sensation, muscle weakness, sleep disturbance, and movement/ambulation impairment, over the 14 days of therapy, as compared with baseline. ${ }^{[44]}$
Roy Freeman et al, have demonstrated efficacy of Pregabalin in six of seven clinical trials. Pooling data from all treatment arms in this analysis adds to our knowledge of the efficacy, safety, and tolerability of Pregabalin for treatment of painful DPN. ${ }^{[45]}$

A 12-week randomised, double-blind, multicenter, placebocontrolled, parallel-group study evaluated the efficacy and safety of Pregabalin in patients with chronic PHN or painful DPN. Both flexible and fixed-dose Pregabalin significantly reduced endpoint mean pain score (primary outcome) versus placebo $(P=0.002, P<0.001)$ and were significantly superior to placebo in improving pain-related sleep interference $(P<0.001)$. These results were consistent with previous studies demonstrating Pregabalin's efficacy, tolerability, and safety for treatment of chronic neuropathic pain associated with DPN or PHN. At optimal balance of efficacy and tolerability Pregabalin provided significant pain relief with reduced risks for AEs and therapy discontinuation. ${ }^{[46]}$

Interestingly, Kanukla et al in Indian population study has highlighted that combination of Pregabalin and Amitriptyline is efficacious and safe in managing chronic low back pain (CLBP) with or without radiculopathy. ${ }^{[47]}$

In correlation with the previous studies in which there was a positive outcome with pain relief with both the drugs Amitriptyline and Pregabalin, this study also proved similar efficacy and safety results. These results allow only the conclusion that the Amitriptyline and Pregabalin combination is effective in treating series of etiologies associated with $\mathrm{NeP}$.

Limitations of our study include the fact that the duration of study was 21 days. This combination is considered for short duration and switched to single neuroanalgesic.

\section{Conclusion}

The current study has drawn a statement that chronic pain implicates multiple pathophysiological mechanisms and the management requires an interdisciplinary approach. Further, numerous mechanisms at multiple levels may involve more than one systemic agent necessary to target relevant mechanisms, and that when two agents are used it is sometimes possible to obtain better analgesia at lower doses and with fewer side effects. Hence, the outcome of this present investigation has thrown light on the efficacy and safety of the combination of Amitriptyline and Pregabalin in pain management.

\section{Disclosure}

This study was sponsored by Centaur Pharmaceuticals Pvt. Ltd. for their brand AmNurite-P, which is a combination of Amitriptyline and Pregabalin. This study was drafted with the medical writing help received from Medical Services Department of Centaur Pharmaceuticals Pvt. Ltd.

\section{References}

[1] NICE C. 173: Neuropathic pain-pharmacological management. The pharmacological management of neuropathic pain in adults in non-specialist settings. 2013 Nov. 


\section{International Journal of Innovative Research in Medical Science (IJIRMS) Volume 04 Issue 01 Jan 2019, ISSN: 2455-8737, Imp. Factor - 4.102 \\ Available online at - www.ijirms.in}

[2] Mao J, Gold MS. Combination drug therapy for chronic pain: a call for more clinical studies. The Journal of Pain. 2011 Feb 28;12(2):157-66.

[3] Freynhagen R, Baron R, Gockel U, Tölle TR. Pain DETECT: a new screening questionnaire to identify neuropathic components in patients with back pain. Current medical research and opinion. 2006 Oct 1;22(10):1911-20.5.

[4] Daousi C, MacFarlane IA, Woodward A, Nurmikko TJ, Bundred PE, Benbow SJ. Chronic painful peripheral neuropathy in an urban community: a controlled comparison of people with and without diabetes. Diabetic Medicine. 2004 Sep 1;21(9):976-82.

[5] Davies M, Brophy S, Williams R, Taylor A. The prevalence, severity, and impact of painful diabetic peripheral neuropathy in type 2 diabetes. Diabetes care. 2006 Jul 1;29(7):1518-22.

[6] Kehlet H, Jensen TS, Woolf CJ. Persistent postsurgical pain: risk factors and prevention. The Lancet. 2006 May 19;367(9522):1618-25.

[7] Smith BH, Torrance N, Bennett MI, Lee AJ. Health and quality of life associated with chronic pain of predominantly neuropathic origin in the community. The Clinical journal of pain. 2007 Feb 1;23(2):143-9.

[8] Bouhassira D, Lantéri-Minet M, Attal N, Laurent B, Touboul C. Prevalence of chronic pain with neuropathic characteristics in the general population. Pain. 2008 Jun 15;136(3):380-7.

[9] Finnerup NB, Attal N, Haroutounian S, McNicol E, Baron R, Dworkin RH, Gilron I, Haanpää M, Hansson P, Jensen TS, Kamerman PR. Pharmacotherapy for neuropathic pain in adults: a systematic review and metaanalysis. The Lancet Neurology. 2015 Feb 28;14(2):16273.

[10] Martinez V, Attal N, Vanzo B, Vicaut E, Gautier JM, Bouhassira D, Lantéri-Minet M. Adherence of French GPs to chronic neuropathic pain clinical guidelines: Results of a cross-sectional, randomized,"e" casevignette survey. PloS one. 2014 Apr 18;9(4):e93855.

[11] Argoff CE. The coexistence of neuropathic pain, sleep, and psychiatric disorders: a novel treatment approach. The Clinical journal of pain. 2007 Jan 1;23(1):15-22.

[12] Cruccu G, Aziz L, Garcia-Larrea L, et al. EFNS guidelines on neurostimulation therapy for neuropathic pain. Eur J Neurol. 2007;14(9):952-970.

[13] Attal N, Cruccu G, Haanpää M, Hansson P, Jensen TS, Nurmikko T, Sampaio C, Sindrup S, Wiffen P. EFNS guidelines on pharmacological treatment of neuropathic pain. European journal of neurology. 2006 Nov 1;13(11):1153-69.

[14] Dworkin RH, O'connor AB, Backonja M, Farrar JT, Finnerup NB, Jensen TS, Kalso EA, Loeser JD, Miaskowski C, Nurmikko TJ, Portenoy RK. Pharmacologic management of neuropathic pain: evidence-based recommendations. Pain. 2007 Dec 5;132(3):237-51.

[15] Gilron I, Watson CP, Cahill CM, Moulin DE. Neuropathic pain: a practical guide for the clinician. Canadian Medical Association Journal. 2006 Aug 1;175(3):265-75.
[16] Moore RA, Derry S, Aldington D, Cole P, Wiffen PJ. Amitriptyline for neuropathic pain and fibromyalgia in adults. The Cochrane Library. 2012 Jan 1.

[17] Sindrup SH, Otto M, Finnerup NB, Jensen TS. Antidepressants in the treatment of neuropathic pain. Basic \& clinical pharmacology \& toxicology. 2005 Jun 1;96(6):399-409.

[18] Basbaum AI, Fields HL. Endogenous pain control mechanisms: review and hypothesis. Annals of neurology. 1978 Nov 1;4(5):451-62.

[19] Sagen, Jacqueline, and Herbert K. Proudfit. "Evidence for pain modulation by pre-and postsynaptic noradrenergic receptors in the medulla oblongata." Brain Research 331.2 (1985): 285-293.

[20] Bryson HM, Wilde MI. Amitriptyline. Drugs \& aging. 1996 Jun 1;8(6):459-76.

[21] Owens MJ, Morgan WN, Plott SJ, Nemeroff CB. Neurotransmitter receptor and transporter binding profile of antidepressants and their metabolites. Journal of Pharmacology and Experimental Therapeutics. 1997 Dec 1;283(3):1305-22.

[22] Schulz P, Turner-Tamiyasu K, Smith G, Giacomini KM, Blaschke TF. Amitriptyline disposition in young and elderly normal men. Clinical Pharmacology \& Therapeutics. 1983 Mar 1;33(3):360-6.

[23] Gupta SK, Shah JC, Hwang SS. Pharmacokinetic and pharmacodynamic characterization of OROS ${ }^{\circledR}$ and immediate-release amitriptyline. British journal of clinical pharmacology. 1999 Jul 1;48(1):71-8.

[24] Tan T, Barry P, Reken S, Baker M. GUIDELINES: Pharmacological management of neuropathic pain in non-specialist settings: summary of NICE guidance. BMJ: British Medical Journal. 2010 Mar 27;340(7748):707-9.

[25] Dworkin RH, Corbin AE, Young JP, Sharma U, LaMoreaux L, Bockbrader H, Garofalo EA, Poole RM. Pregabalin for the treatment of postherpetic neuralgia A randomized, placebo-controlled trial. Neurology. 2003 Apr 22;60(8):1274-83.

[26] Richter RW, Portenoy R, Sharma U, Lamoreaux L, Bockbrader H, Knapp LE. Relief of painful diabetic peripheral neuropathy with pregabalin: a randomized, placebo-controlled trial. The journal of pain. $2005 \mathrm{Apr}$ 30;6(4):253-60.

[27] Freynhagen R, Strojek K, Griesing T, Whalen E, Balkenohl M. Efficacy of pregabalin in neuropathic pain evaluated in a 12-week, randomised, double-blind, multicentre, placebo-controlled trial of flexible-and fixed-dose regimens. Pain. 2005 Jun 30; 115(3):254-63.

[28] Verma V, Singh N, Singh Jaggi A. Pregabalin in neuropathic pain: evidences and possible mechanisms. Current neuropharmacology. 2014 Jan 1; 12(1):44-56.

[29] Taylor CP. The biology and pharmacology of calcium channel alpha 2 -delta proteins. CNS Drug Rev. 2004;10:183-8.

[30] Finnerup NB, Jensen TS. Clinical use of pregabalin in the management of central neuropathic pain. Neuropsychiatric disease and treatment. 2007 Dec; 2007:885.

[31] Gilron I, Jensen TS, Dickenson AH. Combination pharmacotherapy for management of chronic pain: from 
bench to bedside. The Lancet Neurology. 2013 Nov 30;12(11):1084-95.

[32] Moulin DE, Boulanger A, Clark AJ, Clarke H, Dao T, Finley GA, Furlan A, Gilron I, Gordon A, MorleyForster PK, Sessle BJ. Pharmacological management of chronic neuropathic pain: revised consensus statement from the Canadian Pain Society. Pain Research and Management. 2014;19(6):328-35.

[33] O'Connor AB, Dworkin RH. Treatment of neuropathic pain: an overview of recent guidelines. The American journal of medicine. 2009 Oct 31; 122(10):S22-32.

[34] Finnerup NB, Otto M, McQuay HJ, Jensen TS, Sindrup SH. Algorithm for neuropathic pain treatment: an evidence based proposal. Pain. 2005 Dec 5; 118(3):289305.

[35] Dworkin RH, Backonja M, Rowbotham MC, Allen RR, Argoff CR, Bennett GJ, Bushnell MC, Farrar JT, Galer BS, Haythornthwaite JA, Hewitt DJ. Advances in neuropathic pain: diagnosis, mechanisms, and treatment recommendations. Archives of neurology. 2003 Nov 1;60(11):1524-34.

[36] Lynch ME. Antidepressants as analgesics: a review of randomized controlled trials. Journal of Psychiatry and Neuroscience. 2001 Jan; 26(1):30.

[37] Max MB. Antidepressants as analgesics. Pharmacological approaches to the treatment of chronic pain: New concepts and critical issues. 1994.

[38] Max MB. Thirteen consecutive well-designed randomized trials show that antidepressants reduce pain in diabetic neuropathy and postherpetic neuralgia. InPain Forum 1995 Dec 1 (Vol. 4, No. 4, pp. 248-253). Churchill Livingstone.

[39] McQuay HJ, Moore RA. Antidepressants and chronic pain. BMJ: British Medical Journal. 1997 Mar 15;314(7083):763.
[40] McQuay HJ, Tramer M, Nye BA, Carroll D, Wiffen PJ, Moore RA. A systematic review of antidepressants in neuropathic pain. Pain. 1996 Dec 31; 68(2):217-27.

[41] Lynch ME, Watson CP. The pharmacotherapy of chronic pain: a review. Pain Research and Management. 2006;11(1):11-38.

[42] Watson CP, Evans RJ, Reed K, Merskey H, Goldsmith L, Warsh J. Amitriptyline versus placebo in postherpetic neuralgia. Neurology. 1982 Jun 1;32(6):671-671.

[43] Morello CM, Leckband SG, Stoner CP, Moorhouse DF, Sahagian GA. Randomized double-blind study comparing the efficacy of gabapentin with amitriptyline on diabetic peripheral neuropathy pain. Archives of internal medicine. 1999 Sep 13;159(16):1931-7.

[44] Dongre YU, Swami OC. sustained-release pregabalin with methylcobalamin in neuropathic pain: an Indian real-life experience. International Journal General Medicine. 2013 Jan 1;6:413-7.

[45] Freeman R, Durso-DeCruz E, Emir B. Efficacy, Safety, and Tolerability of Pregabalin Treatment for Painful Diabetic Peripheral Neuropathy Findings from seven randomized, controlled trials across a range of doses. Diabetes care. 2008 Jul 1;31(7):1448-54.

[46] Freynhagen R, Strojek K, Griesing T, Whalen E, Balkenohl M. Efficacy of pregabalin in neuropathic pain evaluated in a 12-week, randomised, double-blind, multicentre, placebo-controlled trial of flexible-and fixed-dose regimens. Pain. 2005 Jun 30;115(3):254-63.

[47] Kanukula R, Bansal D, Ghai B. Efficacy and Safety Of Combination Of Pregabalin And Amitriptyline In Patients With Chronic Low Back Pain In Indian Population. Value in Health. 2014 May 1;17(3):A224. 